\title{
A versatile procedure for rapid induction of narcotic addiction in the rat utilizing intravenous injections
}

\author{
ROBERT NUMAN, NELSON SMITH, and HARBANS LAL \\ Department of Pharmacology and Toxicology and Department of Psychology, \\ University of Rhode Island, Kingston, Rhode Island 02881
}

\begin{abstract}
Intermittent injections of morphine sulfate in increasing doses produced reliable narcotic dependence in rats within 6 days. Discontinuation of programmed injections induced withdrawal symptoms which were relieved by narcotic administration and which therefore provided motivation to acquire high rates of operant responding for morphine self-administration.
\end{abstract}

Usually narcotic drugs are administered for weeks or even months to cause reliable dependence in the rat (Bläsig, Herz, Reinhold, \& Zieglgänsberger, 1973; Lal, O'Brien, \& Puri, 1971; Stolerman \& Kumar, 1970; Thompson \& Ostland, 1965; Wikler, \& Pescor, 1967). These procedures are therefore not useful where short-term treatment of experimental animals is desired. Recently, Coussens, Crowder, and Smith (1973) and Teiger (1974) showed that physical dependence on narcotics can be rapidly induced in the rat by either continuous or discontinuous injections of morphine solutions. Following these suggestions, we tested several schedules of injections in order to select a safe and versatile procedure which could be easily applied in behavioral and conditioning studies. Here, we describe an intravenous addiction schedule which we found to cause reliable narcotic dependence and can be utilized in behavioral experiments.

\section{METHOD}

Male hooded rats of the Long-Evans strain, which weighed between 300 and $375 \mathrm{~g}$, were used. Each rat was implanted with an indwelling jugular catheter and housed individually in sound-attenuated behavioral chambers. The catheter was connected by way of a swivel to an injection system located outside the chamber. Animals were free to move in all directions. Food and water were available ad lib and house lighting was alternated on a 12-h day-night cycle. The chambers were placed in air-conditioned rooms and ventilated constantly to maintain an ambient temperature of $23^{\circ} \mathrm{C}( \pm 2)$. The surgical procedure, indwelling cannula, and swivel used were similar to those recently described (Smith \& Davis, 1973).

Morphine sulfate was dissolved in sterile saline. Each injection consisted of $.1 \mathrm{ml}$ of solution delivered automatically over a $10-\mathrm{sec}$ period. The injection schedule is decribed in Table 1.

While six rats were given morphine injections, three additional rats were given only saline injections in order to rule out any effect of stress in causing morphine withdrawal-like symptoms.

The research reported in this paper was supported by Grant DA00418 from National Institute on Drug Abuse, Departments of Health, Education, and Welfare. We would like to thank Mrs. Kathleen McGovern and Miss Jean Mackey for their technical assistance.
Withdrawal symptoms were recorded at $4,8,24,48$, and $72 \mathrm{~h}$ following the last morphine injection. For these measurements, the door of the behavioral chamber was opened, and each animal was individually observed for $30 \mathrm{~min}$ without removing the cannula. Presence of ptosis, piloerection, and writhing were checkmarked. "Wet-dog"-like shakes were counted (Gianutsos, Drawbaugh, Hynes, \& Lal, 1974) and hypothermia was computed from rectal temperatures (Drawbaugh \& Lal, 1974).

In one subject, automatic injections were terminated following addiction, and the animal was allowed access to a lever in the operant chamber. Each leverpress resulted in an injection of morphine $(1.5 \mathrm{mg} / \mathrm{kg})$.

\section{RESULTS}

All rats survived the procedure of addiction. They appeared healthy and consumed normal quantities of food and water throughout the period of addiction. During withdrawal, all of the morphine treated animals showed pronounced abstinence symptoms (Table 2). The withdrawal symptoms began to appear at $4 \mathrm{~h}$ following the last morphine injection and continued throughout the 72-h period of observation. At this time, morphine sulfate $(15 \mathrm{mg} / \mathrm{kg})$ was injected into two rats, and this treatment immediately abolished the withdrawal symptoms. In the remaining rats, the withdrawal symptoms were found to be gradually reduced, until $96 \mathrm{~h}$ when only mild symptoms were present. Withdrawal symptoms, with the exception of some piloerection, did not appear in saline treated animals.

Table 1

Addiction Schedule Used for Intravenous Morphine Administration

\begin{tabular}{|c|c|c|c|}
\hline Day & $\begin{array}{c}\text { Morphine S } \\
\text { Per } \\
\text { Injection }\end{array}$ & $\begin{array}{l}\text { ate }(\mathrm{mg} / \mathrm{kg}) \\
\text { Per Day }\end{array}$ & $\begin{array}{c}\text { Interval } \\
\text { Between } \\
\text { Injections }(h)\end{array}$ \\
\hline $1 *$ & 0 & 0 & 3 \\
\hline 2 & 1.5 & 36 & 1 \\
\hline 3 & 3.0 & 72 & 1 \\
\hline 4 & 7.5 & 90 & 2 \\
\hline $5-7$ & 15.0 & 90 & 4 \\
\hline
\end{tabular}

*Saline injections 
Table 2

Withdrawal Symptoms Following 6 Days of Intravenous Morphine Injections

\begin{tabular}{|c|c|c|c|c|c|c|}
\hline \multirow{2}{*}{$\begin{array}{l}\text { Hours After Last } \\
\text { Morphine } \\
\text { Injection* }\end{array}$} & \multicolumn{3}{|c|}{ Percentage of Rats Showing } & \multicolumn{3}{|c|}{ Mean $\pm \mathrm{SE}$} \\
\hline & Ptosis & Piloerection & Writhing & "Body Shakes"** & Hypothermia $\dagger\left({ }^{\circ} \mathrm{C}\right)$ & Weight Loss $¥$ (g) \\
\hline $4(4)$ & 50 & 50 & 0 & $17 \pm 7$ & $1.09 \pm .44$ & \\
\hline $8(5)$ & 60 & 80 & 80 & $25 \pm 7$ & $.58 \pm .19$ & \\
\hline $24(5)$ & 0 & 80 & 60 & $38 \pm 7$ & $1.13 \pm .21$ & \\
\hline $48(5)$ & 0 & 100 & 60 & $35 \pm 8$ & $1.10 \pm .30$ & \\
\hline $72(5)$ & 0 & 100 & 60 & $34 \pm 9$ & $.84 \pm .19$ & $50 \pm 7$ \\
\hline
\end{tabular}

* Numbers in parentheses indicate number of rats observed.

** "Body shakes" are shaking molements which are typically elicited in an animal drenched in water.

tDifference between rectal temperature recorded at $30 \mathrm{~min}$ after last morphine injection and those recorded at the different withdrawal periods in four rats.

$\neq$ Difference between body weight taken immediately after last morphine injection and that taken at $72 \mathrm{~h}$ of withdrawal.

Leverpressing for self-administration of morphine is illustrated in Figure 1. Within a day after the lever was made available, the previously addicted rat learned to self-administer morphine solutions. Beginning with 50 injections each day, the rat increased the rate of injections which stabilized at about 250 injections a day by Day 10 . This rate of self-administration was maintained for more than a month, at which time the rat was sacrificed.

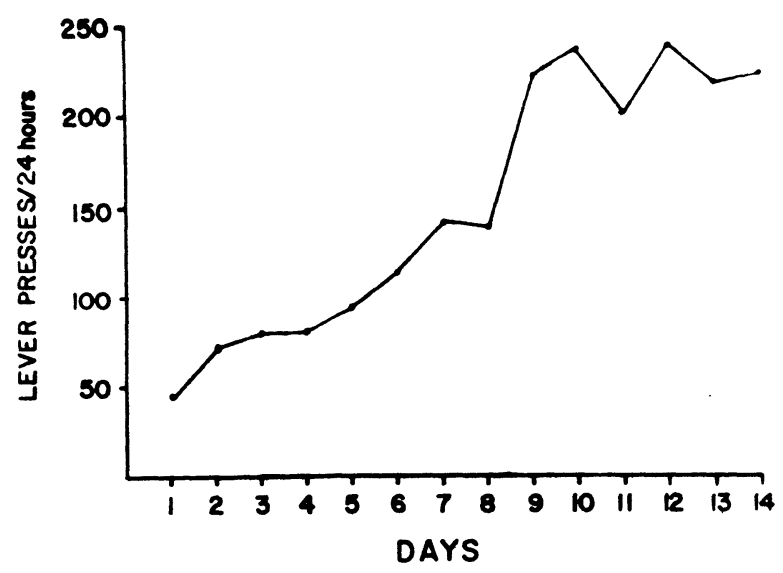

Figure 1. Leverpresses for self-injections of morphine $(1.5 \mathrm{mg} / \mathrm{kg} /$ injection) in a rat previously addicted to morphine sulfate given in terminal doses of $15 \mathrm{mg} / \mathrm{kg} /$ injection every $4 \mathrm{~h}$.

\section{DISCUSSION}

Incremental doses of morphine sulfate injected intravenously over a 6-day period produces reliable narcotic dependence in rats. The symptoms observed in the experimental animals were clearly the result of narcotic withdrawal since they were abolished by the reinstatement of morphine injections and were not seen in control rats injected only with saline.
Since the duration and schedule of morphine injections are rigidly controlled, and the interinjection interval $(4 \mathrm{~h})$ is sufficient to cause withdrawal discomfort, injections can be paired with specific environmental events for conditioning experiments. For this reason, and because of the relatively short time necessary to produce dependence, the programmed intravenous injections are suitable for a variety of behavioral and pharmacological experiments.

\section{REFERENCES}

Bläsig, J., Herz, A., Reinhold, K., \& Zieglgänsberger, S. Development of physical dependence on morphine in respect to time and dosage and quantification of the precipitated withdrawal syndrome in rats. Psychopharmacologia (Berl.), $1973,33,19-38$.

Coussens, W. R., Crowder, W. F., \& Smith, S. G. Acute physical dependence upon morphine in rats. Behavioral Biology, 1973 . 8, 533-543.

Drawbaugh, R. B., \& Lal, H. Reversal by narcotic antagonist of a narcotic action elicited by a conditional stimulus. Nature, $1974,247,65-67$.

Gianutsos, G., Drawbaugh, R. B., Hynes, M. D., \& Lal, H. Behavioral evidence for dopaminergic supersensitivity after chronic haloperidol. Life Sciences, 1974, 14, 887-898.

Lal, H., O'Brien, J., \& Puri, S. K. Morphine-withdrawal aggression: sensitization by amphetamine. Psychopharmacologia (Berl.), 1971, 22, 217-223.

Smith, S. G., \& Davis, W. M. Behavioral Control by stimuli associated with acquisition of morphine self-administration. Behavioral Biology, 1973, 9, 777-780.

Stolerman, I. P., \& Kumar, R. Preferences for morphine in rats: Validation of an experimental model of dependence. Psychopharmacologia (Berl.), 1970, 17, 137-150.

Teiger, D. G. Induction of physical dependence on morphine, codeine and meperidine in the rat by continuous infusion. Journal of Pharmacology and Experimental Therapeutics, $1974,190,408-415$.

Thompson, T., \& Ostlund, W. Susceptibility to readdiction as a function of the addiction and withdrawal environments. Journal of Comparative and Physiological Psychology, 1965, 60, 388-392.

Wikler, A., \& Pescor, F. T. Classical conditioning of a morphine abstinence phenomenon, reinforcement of opioid-drinking behavior and "relapse" in morphine addicted rats. Psy chopharmacologia (Berl.), 1967, 10, 255-284.

(Received for publication December 30, 1974; accepted February 15, 1975.) 